\title{
Identifikasi Nyamuk Anopheles Sebagai Vektor Malaria dari Survei Larva di Kenagarian Sungai Pinang Kecamatan Koto XI Tarusan Kabupaten Pesisir Selatan
}

\author{
Suci Lestari ${ }^{1}$, Adrial $^{2}$, Rosfita Rasyid ${ }^{3}$
}

\begin{abstract}
Abstrak
Malaria merupakan salah satu masalah kesehatan global yang menimbulkan angka kesakitan tinggi dan kematian terutama pada daerah beriklim tropis dan subtropis. Kenagarian Sungai Pinang merupakan salah satu daerah endemik malaria yang didukung oleh topografinya yang terdiri dari daerah pantai, rawa, sungai, daerah pertanian dan area pemukiman. Jenis rancangan penelitian adalah survei deskriptif dengan populasi semua larva nyamuk yang ditemukan di beberapa tempat perindukan. Sampel adalah semua larva nyamuk Anopheles yang tertangkap melalui proses cidukan. Identifikasi nyamuk anopheles dengan memakai buku acuan Stroker dan Koesoemawinangoen. Data dianalisis secara manual dan disajikan dalam bentuk tabel distribusi frekuensi. Penelitian dilakukan di Kenagarian Sungai Pinang dari Oktober 2011 sampai Maret 2012. Hasil penelitian adalah 5 spesies nyamuk anopheles yaitu An. aconitus, An. barbirostris, An. kochi, An. subpictus dan An. Sundaicus. Tempat perindukan yaitu kolam bekas kurungan ikan, lagoon, rawa-rawa, kubangan kerbau, tambak sawah dan sungai. Kesimpulan penelitian ini ialah rata-rata kepadatan larva anopheles tertinggi adalah An. subpictus yaitu 4,95 ekor/cidukan dengan tempat perindukan yang memiliki rata rata kepadatan larva Anopheles tertinggi yaitu kolam bekas kurungan ikan dengan 27,93 ekor/cidukan.
\end{abstract}

Kata kunci: nyamuk anopheles, larva anopheles, tempat perindukan, kepadatan larva

\section{Abstract}

Malaria is a global health problem that causes high morbidity and mortality, especially in the tropics and subtropics areas. Kenagarian Sungai Pinang is one of endemic areas which supported by the topography of the area, consists of beaches, marshes, rivers, agricultural area and a residential area. Research conducted in Kenagarian Sungai Pinang from October 2011 to March 2012. Design of this study was a descriptive survey with a population was any mosquito larvae were found in some breeding places. The samples were all Anopheles larvae that caught through detention. Identification of the Anopheles mosquito using Stroker and Koesoemawinangoen (1950) reference books. The data were analyzed manually and presented in the form of a frequency distribution table. The results were five species of Anopheles mosquito; An. aconitus, An. barbirostris, An. kochi, An. subpictus dan An. Sundaicus. Seven breeding place were ex-fish cages ponds, lagoon, marsh, buffalo wallow, embankment, rice fields and rivers. The conclusion of this research are the highest larva density is An. subpictus with 4,95 larvae/detention and breeding place that has highest density of Anopheles larvae is ex-fish cage ponds with 27,93 larvae/detention.

Keywords: anopheles mosquito, larvae anopheles, breeding places, larvae density

Affiliasi penulis: 1. Prodi Profesi Dokter FK UNAND (Fakultas Kedokteran Universitas Andalas Padang), 2. Bagian Parasitologi FK UNAND, 3. Bagian IImu Kesehatan Masysrakat FK UNAND. Korespondensi: Bagian Parasitologi FK UNAND

\section{PENDAHULUAN}

Malaria masih menjadi masalah kesehatan global yang menimbulkan angka kesakitan yang tinggi serta kematian terutama pada kelompok risiko tinggi 
disamping dampak sosial ekonominya terhadap penduduk terutama pada negara berkembang dengan iklim tropis dan subtropis. ${ }^{1,2}$ Malaria merupakan salah satu indikator dari target Pembangunan Milenium (MDGs) dan masih menjadi endemik di 106 negara di seluruh dunia dan menyebabkan kematian 80.000 setiap tahunnya. ${ }^{3}$

Kenagarian Sungai Pinang merupakan salah satu nagari di Kecamatan Koto XI Tarusan yang menjadi daerah endemik malaria. Hal ini didukung oleh topografinya yang terdiri dari dataran rendah dipinggir pantai, adanya lagoon (rawa yang terisi air jika terjadi air pasang), parit, dan rawa rawa air tawar, ditambah lagi dengan adanya kubangan kerbau di belakang rumah rumah penduduk. Semua hal tersebut menjadi tempat perindukan yang baik bagi vektor nyamuk malaria. ${ }^{4}$

Indonesia memiliki 80 spesies Anopheles tetapi hanya 24 spesies yang terbukti membawa parasit malaria. Berdasarkan penelitian yang pernah dilakukan di Sumatera Barat yaitu di Kenagarian Api Api Kecamatan Bayang, Kenagarian Sungai Pinang Kecamatan Koto XI Tarusan, Kabupaten Pesisir Selatan ditemukan empat spesies larva yaitu Anopheles aconitus, An. kochi, An. subpictus dan An. sundaicus dengan lima tempat perindukan yang terdiri dari lagoon, kubangan kerbau, genangan air di pinggir jalan, bak bekas kurungan ikan pinggir pantai dan rawa rawa di sekitar rumah penduduk. ${ }^{4}$

Berdasarkan tempat perindukannya, vektor malaria dapat dikelompokkan dalam tiga tipe yaitu berkembang biak di daerah persawahan, perbukitan/hutan dan pantai/aliran sungai. Perilaku vektor malaria seperti tempat berkembang biak atau tempat perindukan sangat penting diketahui untuk pengambil keputusan sebagai dasar pertimbangan untuk menentukan intervensi dalam pengendalian vektor. ${ }^{5,6}$

Masih tingginya kasus di daerah Sungai Pinang dan adanya hubungan erat antara tempat perindukan yang terdapat disekitar pemukiman dan kepadatan larva nyamuk dengan insiden malaria dan usaha pengendalian atau pemberantasan malaria maka penulis merasa tertarik untuk melakukan penelitian. Hal ini bertujuan untuk mengetahui spesies nyamuk
Anopheles, kepadatan larva atau jentik serta tempat perindukan larva di daerah Sungai Pinang.

Kepentingan penelitian ini adalah untuk mendapatkan informasi terbaru karena konfirmasi (pemetaan) ulang vektor perlu secara terus menerus dilakukan sehingga diketahui perilaku vektor malaria seperti spesies, tempat perindukan, kepadatan sebagai dasar petimbangan untuk menentukan intervensi dalam pengendalian vektor yang lebih efektif kedepannya. ${ }^{6}$

\section{METODE}

Penelitian ini menggunakan rancangan survei deskriptif yang diilakukan di Kenagarian Sungai Pinang Kecamatan Koto XI Tarusan Kabupaten Pesisir Selatan dari Oktober 2011 - Maret 2012.

Sampel penelitian yang digunakan adalah semua larva nyamuk Anopheles yang tertangkap pada survei larva dengan interval pengambilan dua minggu sekali. Larva ditangkap di genangan genangan air yang menjadi tempat perindukannya. Larva kemudian dipelihara sampai menjadi nyamuk dewasa. Setelah dewasa maka nyamuk ini diidentifikasi di Laboratorium Parasitologi Fakultas Kedokteran Universitas Andalas.

Data yang telah didapat dianalisis secara manual, kemudian disajikan dalam bentuk tabel distribusi frekuensi.

\section{HASIL dan PEMBAHASAN}

Tabel 1. Spesies nyamuk anopheles yang ditemukan berdasarkan survei larva di Kenangarian Sungai Pinang

\begin{tabular}{lll}
\hline No & Jenis Spesies & Jumlah \\
\hline 1 & An. aconitus & 516 \\
2 & An. barbirostris & 324 \\
3 & An. kochi & 505 \\
4 & An. subpictus & \\
5 & An. sundaicus & 3211 \\
\hline
\end{tabular}

Sesuai Tabel 1, dalam penelitian ini ditemukan lima spesies nyamuk Anopheles di Kenagarian Sungai Pinang yaitu An. sundaicus, An. subpictus, An. kochi, An. aconitus, dan An. barbirostris. 
Dibandingkan dengan penelitian sebelumnya pada daerah endemik yang memiliki topografi daerah yang hampir sama seperti pada penelitian Adrial dan Nurhayati (2002) di Desa Api-Api Kecamatan Bayang Kabupaten Pesisir Selatan menemukan empat spesies nyamuk Anopheles dimana semuanya juga ditemukan di Kenagarian Sungai Pinang yaitu An. subpictus, An. sundaicus, An. kochi, dan An. acconitus. ${ }^{4}$

$\mathrm{Hal}$ yang sama pada penelitian di luar Sumatra barat seperti penelitian yang dilakukan Mading Majematang pada tahun 2010 ditemukan sembilan spesies dimana tiga spesies sama dengan yang ditemukan di Sungai Pinang yaitu An. aconitus, An. subpictus dan An. sundaicus dengan lagoon sebagai tempat perindukan yang dominan. ${ }^{7}$ Penelitian lainnya di Kecamatan Padang Cermin Lampung Selatan oleh Safitri Amalia pada tahun 2009 menemukan sembilan spesies nyamuk Anopheles, dimana lima spesies diantaranya sama dengan spesies yang ditemukan pada penelitian ini dengan $A n$. sundaicus dan $A n$. subpictus juga menjadi yang lebih dominan. ${ }^{8}$

Tabel 2. Tempat perindukan nyamuk anopheles berdasarkan survei larva di Kenagarian Sungai Pinang

\begin{tabular}{llr}
\hline No & Tempat Perindukan & Jumlah \\
\hline & Kolam bekas kurungan & \\
1 & ikan & 1607 \\
2 & Lagoon & 2307 \\
3 & Rawa-rawa & 1399 \\
4 & Kubangan kerbau & 1023 \\
5 & Tambak & 1399 \\
6 & Sawah & 805 \\
7 & Sungai & 321 \\
\hline
\end{tabular}

Berdasarkan Tabel 2, terdapat tujuh tempat perindukan nyamuk Anopheles yang terdapat di Kenagarian Sungai Pinang yaitu kolam bekas kurungan ikan, lagoon, rawa-rawa, kubangan kerbau, tambak, sawah dan sungai.

Penelitian sebelumnya di daerah yang sama oleh Adrial et al pada tahun 2001 ditemukan 5 tempat perindukan yaitu lagoon, bak bekas kurungan ikan, kubangan kerbau, rawa dan genangan air pinggir jalan. $^{9}$
Kepadatan larva Anopheles di Kenagarian Sungai Pinang berdasarkan jenis tempat perindukan dan jenis spesies tersebut dapat dilihat pada Tabel 3.

Tabel 3. Kepadatan larva nyamuk anopheles berdasarkan tempat perindukan dan jenis spesies di Kenagarian Sungai Pinang

\begin{tabular}{|c|c|c|c|c|c|c|c|c|}
\hline \multirow{2}{*}{$\begin{array}{c}\text { Tempat } \\
\text { Perindu } \\
\text { kan }\end{array}$} & \multirow{2}{*}{$\begin{array}{l}\text { Jmh } \\
\text { Cidu } \\
\text { kan }\end{array}$} & \multicolumn{2}{|c|}{$\begin{array}{c}\text { Larva } \\
\text { Anopheles }\end{array}$} & \multicolumn{5}{|c|}{ Spesies Anopheles } \\
\hline & & Jmh & $\begin{array}{c}\text { Larva } \\
\text { (ekor/cid } \\
\text { ukan) }\end{array}$ & $\begin{array}{c}\text { An. } \\
\text { aconit } \\
\text { us }\end{array}$ & $\begin{array}{c}\text { An. } \\
\text { barbiro } \\
\text { stris }\end{array}$ & $\begin{array}{c}A n \\
\text { kochi }\end{array}$ & $\begin{array}{c}\text { An. } \\
\text { subpic } \\
\text { tus }\end{array}$ & $\begin{array}{c}\text { An. } \\
\text { sundaic } \\
\text { us }\end{array}$ \\
\hline $\begin{array}{l}\text { Kolam } \\
\text { kurunga } \\
\text { n ikan }\end{array}$ & 60 & 1674 & 27,93 & 248 & 112 & 157 & 120 & 168 \\
\hline Lagoon & 120 & 2307 & 19,23 & 0 & 53 & 97 & 78 & 93 \\
\hline $\begin{array}{l}\text { Rawa- } \\
\text { rawa }\end{array}$ & 120 & 1399 & 11,66 & 156 & 92 & 143 & 64 & 138 \\
\hline $\begin{array}{l}\text { Kubang } \\
\text { an } \\
\text { kerbau }\end{array}$ & 60 & 593 & 9,88 & 0 & 0 & 0 & 1394 & 913 \\
\hline Tambak & 120 & 1023 & 8,53 & 112 & 0 & 87 & 433 & 391 \\
\hline Sawah & 120 & 805 & 6,71 & 0 & 67 & 21 & 635 & 676 \\
\hline Sungai & 120 & 321 & 2,68 & 0 & 0 & 0 & 842 & 832 \\
\hline Jumlah & 720 & 8122 & 11,28 & 516 & 324 & 505 & 3566 & 3211 \\
\hline Kepada & & & 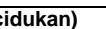 & 0,72 & 0,45 & 0,70 & 4,95 & 4,46 \\
\hline
\end{tabular}

Pada Tabel 3 terlihat bahwa An.subpictus dan An. sundaicus lebih dominan dibanding spesies lain dengan rata rata kepadatan larva tertinggi yaitu $A n$. subpictus dengan 4,95 ekor/cidukan.

Nyamuk An. subpictus berkembangbiak di zona pantai yang berair payau yang memiliki ganggang ataupun lumut. Walaupun pada penelitian ini $A n$. subpictus ditemukan pada semua jenis tempat perindukan tetapi kolam bekas kurungan ikan dan lagoon merupakan tempat perindukannya yang memiliki rata-rata kepadatan larva tertinggi. Pada umumnya tempat perindukan An. subpictus merupakan tempat terbuka yang terkena sinar matahari. $^{10}$

Kepadatan larva masing masing spesies Anopheles yang ditemukan berdasarkan tempat perindukannya juga dapat dilihat pada Tabel 3 dengan rata rata kepadatan larva tertinggi terdapat di kolam bekas kurungan ikan dengan 27.93 ekor/cidukan.

Penelitian Dachlan pada tahun 2005 juga menemukan kolam bekas kurungan ikan sebagai tempat perindukan nyamuk yang memiliki kepadatan larva tertinggi di Dusun Sayong dan Longlongan. ${ }^{11}$ 
Pada kolam bekas kurungan ikan, $A n$. subpictus dan $A n$. sundaicus kepadatan larvanya sangat tinggi. Hal ini berkaitan dengan kondisi daerah penelitian yang sebagian besar merupakan daerah tepi pantai dengan pekerjaan penduduk sebagai nelayan, An. subpictus dan An. sundaicus merupakan spesies dengan tempat perindukan di zona pantai ${ }^{2}$.

Dibandingkan dengan penelitian sebelumnya di daerah yang sama oleh Adrial pada tahun 2005 yang juga menemukan $A n$. subpictus dan An. sundaicus sebagai dua tertinggi kepadatan larvanya tetapi pada penelitian tersebut tempat perindukan yang lebih tinggi kepadatannya adalah lagoon. ${ }^{12}$ Penelitian lainnya oleh Majematang di Desa Selong Belanak Kab. Lombok Tengah NTB juga menemukan lagoon sebagai tempat perindukan dengan kepadatan larva tertinggi. $^{7}$

An. subpictus dan An. sundaicus selalu secara bersamaan terdapat pada semua jenis tempat perindukan (Tabel 3). Penelitian lainnya yang juga menemukan An. subpictus dan An. sundaicus selalu ditemukan bersama adalah penelitian Yotopronoto et al pada tahun 1995 di Sekotong Lombok yang menemukan ke dua spesies tersebut selalu ditemukan bersama di lagoon dari lima jenis tempat perindukan. ${ }^{13}$

Penelitian Adrial et al pada tahun 2001 di Kecamatan Koto XI Tarusan juga mendapatkan hal yang sama pada lima jenis tempat perindukan yang ditemukan. ${ }^{9}$ Hal ini terjadi karena kesamaan prilaku dari kedua jenis spesies tersebut untuk dapat menyesuaikan diri terhadap lingkungan yang berbeda beda kadar garamnya. ${ }^{14}$ Lima spesies yang ditemukan 4 diantaranya merupakan vektor malaria di Sumatra yaitu An. sundaicus, An. subpictus, An. aconitus dan An. Kochi. ${ }^{15}$

Identifikasi jenis spesies nyamuk Anopheles dalam penelitian ini perlu dilakukan dalam usaha perencanaan dan pengendalian vektor malaria dimana masing masing spesies memiliki perbedaan tempat perindukan, bionomik dan faktor faktor yang mempengaruhinya sehingga pengendalian malaria melalui pengendalian vektor akan lebih efektif.

\section{KESIMPULAN}

Ditemukan lima spesies nyamuk Anopheles yaitu An. aconitus, An. barbirostris, An. kochi, An. subpictus, An. sundaicus dan terdapat tujuh tempat perindukan (breeding place) larva Anopheles yaitu kolam bekas kurungan ikan, lagoon, rawa-rawa, kubangan kerbau, tambak, sawah dan sungai.

Kepadatan larva dari ke lima spesies dari yang tertinggi sampai yang terendah adalah $A n$. subpictus, An. sundaicus, An. aconitus, An. kochi dan An. barbirostris sedangkan kepadatan larva berdasarkan tempat perindukan dari yang tertinggi sampai terendah yaitu kolam bekas kurungan ikan, Lagoon, rawa-rawa, kubangan kerbau ,tambak, sawah dan sungai.

\section{DAFTAR PUSTAKA}

1. WHO. World malaria report. Geneva: WHO; 2009.

2. Harijanto P. Malaria epidemiologi, patogenesis, manifestasi klinis dan penanganan. Jakarta: EGC; 2009.

3. WHO. World malaria report. Geneva: WHO; 2010.

4. Adrial, Nurhayati. Fauna nyamuk anopheles daerah endemik malaria di Api-Api Kecamatan Bayang Kabupaten Pesisir Selatan Propinsi Sumatera Barat. Laporan Penelitian Dosen Muda (BBI) Tahun Anggaran 2002, No.005/ LIT/BPKSDM/IV/2002 Fakultas Kedokteran Andalas.2002.

5. Sutanto, Inge, Ismid IS, Sjarifuddin PK, Sungkar S. Parasitologi kedokteran. Edisi ke-4, Jakarta: Balai Penerbit FKUI: 2008.hlm.189-255.

6. Depkes RI. Pedoman ekologi dan aspek prilaku vektor. Jakarta: Dit.Jen PPM dan PL; 2009.

7. Majematang M. Survei karakteristik tempat perkembangbiakan anopheles spp di Desa Selong Belanak Kecamatan Praya Barat Kabupaten Lombok Tengah Nusa Tenggara Barat tahun 2010.2011.

8. Safitri A. Habitat perkembangbiakan dan beberapa aspek prilaku Anopheles sundaicus di Kecamatan Padang Cermin Lampung Selatan (tesis). Bogor: Institut Pertanian Bogor; 2009. 
9. Adrial, Edison, Nurhayati, Oktarina V, Williana $H$. Bionomik nyamuk anopheles dalam rangka pengendalian vektor malaria di Kecamatan Koto XI Tarusan, Kabupaten Pesisir Selatan. Laporan Hibah Penelitian Program DUE-Like Tahun Anggaran 2001, No. 32/ DL-SK/UNAND/VIII-2001 Fakultas Kedokteran Universitas Andalas Padang. 2001.

10. Harijanto $P$, Nugroho A, Gunawan CA. Malaria dari molekuler ke klinis. Edisi ke-2, Jakarta: EGC 2009.hIm.1-39.

11. Dachlan YP, et al. Malaria endemic patterns on Lombok and Sumbawa Islands Indonesia. Tropical Medicine and Health. 2013;33(2):105-13.

12. Adrial, Harminarti N. Fluktuasi padat populasi Anopheles subpictus dan Anopheles sundaicus di
Daerah Endemik Kenagarian Sungai Pinang Kecamatan Koto XI Tarusan, Kabupaten Pesisir Selatan. Laporan Penelitian Dosen Muda (BBI) tahun Anggaran 2005, No.018/SPPP/PP/DP3M/IV/ 005 Fakultas Kedokteran Andalas.2005.

13. Yotopranoto S, Bedryman YP, Dachlan. Anopheles mosqquito fauna in the malaria endemic area in Sekotong Subdistric, West Lombok Regency, West Nusa Tenggara Province Indonesia. Majalah Kedokteran Tropis Indonesia.1995;8(1-2):114-22.

14. Hoedojo. Bionomik anopheles subpictus, khusus mengenai peranannya sebagai vektor malaria di Jengkalang, Flores. Majalah Parasitologi Indonesia. 1995; 5: 47-56.

15. Depkes RI. Survei entomologi malaria. Jakarta: Dirjen P2M.PLP;1990. 